\title{
The use of the death trope in peer culture play: Grounds for rethinking children and childhood?
}

Rachel Rosen

UCL Institute of Education

Room 301

Social Science Research Unit 18 Woburn Square

London

WC1H ONR

Telephone: 02079115332

Email: r.rosen@ioe.ac.uk

Biographical note: Rachel Rosen is a Lecturer in the Sociology of Childhood at the UCL Institute of Education, London. Her research is concerned with the impact of intersecting inequalities on children's everyday lives, including the ways in which childhoods are classed, 'raced', gendered and generationed. She explores these themes in relation to children's contributions to formal and informal economies, educational institutions, and play/peer cultures. 


\title{
The use of the death trope in peer culture play: Grounds for rethinking children and childhood?
}

\begin{abstract}
:
Dying and death in children's imaginative play is often subjected to literal interpretation, seen as evidence of meaning-making about death or a form of catharsis. Viewed in this light, children's enactment of uncaused and reversible deaths in ludic activity is considered evidence of developmental 'immaturity'. Such interpretations, however, fundamentally misplace the contestive and transformative aspects of play (Henricks, 2006). In contrast, this paper argues for the importance of figurative interpretations of children's play. Drawing on data generated in an ethnographic study at an early years setting in West London, it will be suggested that the death trope served as a generative metaphor in the peer culture, its everyday world characteristics provoking relatively stable responses in the face of uncertainties and ambiguities encountered in ludic activity. The use of the death trope made intimate, caring touch between children permissible, rather than just a by-product of small play spaces filled with many bodies.
\end{abstract}

Keywords: imaginative play, death, peer culture, touch, childhood, generative metaphor

Children's imaginative play about death and dying is often viewed with discomfort by adults, at very least in many highly industrialised countries. It appears disconcerting as a topic of play in light of dominant views of childhood as an idealised time of happiness and freedom from concern. As this paper will demonstrate, regardless of potential adult unease, children continue to engage in imaginative play about death and dying. This raises important questions about how play about death is understood and the implications of various ways of conceptualising death play for child players themselves. The presence of dying and death in children's play is generally subjected to literal interpretation, accounted for as a form of meaning-making about death (e.g. Löfdahl, 2005) or a form of catharsis (e.g. Bateman, Danby and Howard, 2013; Holland, 2003), and by corollary, a window into children's deepseated fears and pre-occupations. Singular adherence to such literal interpretations, it will be argued, run the risk of constituting children as developmentally 'immature', disturbed or even pathological in their possession of 'inappropriate' knowledge. It will be further suggested that such literal interpretations fundamentally misrecognise the figurative nature of play, and 
by default serve to render invisible players' meanings and uses of the death trope in their transformative efforts in the ludic realm 1 .

\section{The sequestration of death from childhood}

Discomfort with children's play about death and dying is rooted in part in the increasing sequestration of death in advanced capitalist countries. Here, death is 'prejudged as a "pornographic" event that should be veiled' (Lee, 2008, p.745). Whilst the extent to which death taboos exist continues to be a subject of debate (e.g. Arnason and Hafsteinsson, 2003), there does seem to be agreement that death and dying have been increasingly moved from people's homes and daily lives to be managed by professionals within civil institutions. Children in particular are often sheltered from death and dying (Stanley and Wise, 2011), indicating that while taboos about death may be generally lifting they take on specific resonances as they collide with particular conceptions of childhood. Death and sexuality are two bodies of knowledge which are considered particularly 'difficult' for children, leading Robinson (2013, p.23) to argue: 'There is a prevailing perception that children should be sheltered from this knowledge for as long as possible in order to avoid any stress or trauma that might be associated with premature access to this information.' Here, adult imaginaries about childhood as a time of innocence, not to be sullied by the harsh realities of the adult world, come into play.

As Dahlberg et al. (2007, p.45) point out, conceptualisations of childhood as a "golden age of innocence' are often productive of pedagogical environments that focus on 'protection, continuity, and security'. The corollary of such views is that childhood, and the territories in which childhood is segregated, are generally romanticised as 'happy' spatial-temporal sites (Boyden, 1997) which adults are expected to maintain. For instance, early childhood settings in England are instructed to promote 'a secure, safe and happy childhood' (DCSF, 2008, p.7). In such a context, or indeed in relation to play more generally which is often characterised as 'fun' and 'pleasurable' (Fromberg, 2002; for a critical perspective see Grieshaber and McArdle, 2010), themes of dying and death in children's play can come to seem decidedly out of place.

\section{Literal interpretations of death in children's play}

Despite attempts to sequester death and dying from children's everyday lives, there is recognition that such themes do, however, occupy children's imaginative play. In seeking to

\footnotetext{
1 The term 'ludic' is employed synonymously with 'play' throughout this article. This is not to discount the possible presence of 'epistemic play' or indeed to re-instantiate a binary typology of play. The choice of terms is due to the emphasis of the article on imaginative rather than problem-solving aspects of play, the latter often being associated with the term 'epistemic play' (Wood, 2013).
} 
account for and analyse such ludic themes, much of the early childhood play literature offers a literal interpretation of the presence of death. One such line of analysis comes from the psychoanalytic tradition where play about death is viewed as a form of catharsis for dealing with fears about death and traumas in the everyday world (Bateman, Danby and Howard, 2013; Goldstein, 1995; Holland, 2003). An alternative perspective is offered within what can broadly be characterised as socio-cultural literature on play. Working within this tradition, Löfdahl (2005) emphasises play as a mode for shared meaning-making. In analysing a play episode in a Swedish preschool in which players enact a series of funeral sequences, she argues that players bring together their 'scattered' understandings of the characteristics of death in order to co-construct new knowledge about mortality, causality, and death rites. Studying children's developing understandings of death through observation of their play has a history within developmental traditions. In one such study, 3-7-year-old children were observed playing after being given a doll accompanied by different 'stimulus statements' including: 'The doll was very sick and is now dead' (Wass et al., 1983). The researchers found that children's understandings of death were similar in both the play scenario and verbal interviews; furthermore, these confirmed 'well-established' developmental trajectories of children's of concepts of death.

Whilst these accounts offer different explanations for the presence and implications of enactments of dying and death in play, they share the view that dying and death in play have a direct and even transparent correspondence to dying and death in the everyday world; indeed this imaginative play is considered to be fundamentally about dying and death. Certainly, play about dying may allow for catharsis and meaning-making and the argument here is not intended to deny, but rather supplement, these interpretations. To reduce play to literal interpretations, however, provides an incomplete picture as it misses key aspects of imaginative play, including its complex unpredictability (Wood, 2012) in which meaningmaking is by no means assured and the contestive nature of playful activity which allows for the acting out of the impossible (see further discussion below).

Asserting the developmental and educational functions of play, what Sutton-Smith (1997) refers to as a rhetoric of 'play as progress', has achieved a particular hegemonic status within the academic disciplines of psychology and education as well as their popular offshoots. As Wood (2012) points out, however, there are significant differences between the potential outcomes of play and what imaginative play means for those who engage in it. The danger of conflating the two is that those elements of play which always exceed any progress narrative - perhaps particularly acute in play which is considered irrational or disjointed including much play about dying, death, and revival - may be ignored or marginalised. There may even be attempts to restrain such play for instrumental purposes 
given that such theories 'provide rationalization for the adult control of children's play' (Sutton-Smith, 1997, p.49).

Perhaps more significantly for the argument being put forward in this article, solely interpreting children's death play along literal lines runs the risk of substantiating deficit views of childhood. On one level, children may be pathologised to an extent for being in possession of what is constituted as 'adult' knowledge and concerns. The point here is not to argue that all proponents of a catharsis thesis of death play, for instance, pathologise children, but to indicate the way such a thesis interacts with dominant conceptions of childhood innocence. This constellation of discourses can serve to render children who engage in death play as troubled, or at risk of becoming deeply troubled as a result of being introduced to such 'unnatural knowledge', and therefore in need of adult intervention to care for what is constituted as an un-childlike fear.

Almost contradictorily, literal interpretations may render children as possessing developmentally immature understandings of death rather than, as previously discussed, knowledge construed as being beyond their years. If dying is treated as a reversible process in play, for instance when children enact death revivals, this may be cited as evidence of inaccurate understandings of mortality. Developmental theories suggest that many children under five are unable to understand that death is final and irreversible, inevitable for all living things, and has internal causes. These misunderstandings, it is argued, are linked to developmental immaturity, specifically an inability to think abstractly where 'fuzzy logic' is accordingly supplemented with fantasy (e.g. see Cox, Garrett and Graham, 2004/2005 for an example of this argument). At stake here is that children's understandings of complex phenomenon are being evaluated as lacking a 'mature concept' of death on the basis of imaginative activity.

A literary comparison can highlight the problematic here: an analogous claim about imaginative activity undertaken by an adult might be to suggest that the Irish writer Bram Stoker was unable to think abstractly or understand fundamental characteristics of death because Lucy - as Count Dracula's first victim - was revived from death, albeit in vampire form. The point here is that there are often significant differences between the perspective from which the imaginative activity of adults and children is interpreted. If a child's imaginative activity in play is analysed from only a literal, developmental perspective focusing on how imaginative activity compares to the constraints of the everyday world, it will likely seem to be lacking in some manner given the fantastical character of imagination. Not only do literal interpretations provide an incomplete picture of children's play about dying and death then but these can serve to substantiate deficit views of childhood. At very least, this 
compels consideration of additional ways of conceptualising such play: this article will suggest that figurative understandings of ludic activity offer one such possibility.

\section{Figurative approaches to play}

Play, argues Henricks (2006, p.182) in developing a sociological perspective on ludic activity, can be characterised as a 'transformative' form of action. Henricks (2006, p.185) puts this in the following manner: 'To play is to interrupt the flow of events, to seize themes from those and other settings, and to apprehend these themes in distinctive ways.' It is in this process, where people pull apart and rebuild worlds in different ways, that perception and meaning are separated, argued Vygotsky (1978). In other words, a player is not constrained by the 'literal' meaning of an object or phenomenon. Whilst the use of death in play makes reference to death outside of the play, the meanings it is given in the ludic world rather than the everyday world assume importance. Such symbolic behaviour allows players to engage with the world in the 'enacted subjunctive' (Sutton-Smith, 1997, p.29) full of, theoretically at least, open possibility and an 'as if' or 'what if' attitude (Fromberg and Bergen, 2006). As Sutton-Smith (1997, p.158) argues:

Children's play fantasies are not meant only to replicate the world, nor to be only its therapy; they are meant to fabricate another world that lives alongside the first one and carries on its own kind of life, a life often much more emotionally vivid than mundane reality.

In this way, play can be characterised - argues Sutton-Smith (1997) - by its ambiguity. This includes the ambiguity of the reference, for instance people are confronted with the question of whether players are really hurt or only pretending, and the ambiguity of intent, for instance whether players think they can revive the dead in the everyday world in the way they are doing in play or only think this is possible in the ludic realm. Notably in this formulation is the sense in which the references in play are connected to the everyday world - indeed this is what lends them their potency- at the same time as being fundamentally outside of it. This ambiguity is, in large part, what makes play a 'tension-filled space' (Henricks, 2006, p.218).

As a form of interaction then, play is 'contestive'. This is not a reference to play as competitive or antagonistic but an understanding of play as involving a dialogic back and forth between a player and the world (Henricks, 2006). Because play involves others - as well as unstable and shifting meanings, acts, and narratives - it is an uncertain enterprise that is only possible to maintain if someone or something 'responds in satisfying ways' (Henricks, 2006, p.201). A player who makes an assertion into the social and physical world, dropping to the ground in death for example, must adjust to the unexpected and even startling responses her/his contestations engender. 
This conceptualisation of play, as the enactment of movable meanings which reconfigure the world in new ways, suggests a way of viewing children's play about death which moves beyond literal interpretations. Instead, it prompts consideration of the use of 'death' from a figurative perspective. Understanding children's play about dying and death as a contestive assertion into the social world allows for examination of the transformative meanings which such play invokes in the ludic realm and the conditions of possibility it produces in players' on-going engagements with others.

\section{Generating data}

This view of play as transformative, contestive, and figurative will be utilised in examining data generated in an ethnographic study investigating children's imaginative play about death and violence. As a research approach, ethnography emphasises intensive study of everyday contexts over a period of time as a way to gain detailed insights into people's perspectives and practices, as well as social processes (Hammersley and Atkinson, 2007). Participant observation is central to ethnography and an 'insider' role is considered important in generating in-depth knowledge. This is particularly the case with controversial activity which is, literally and metaphorically, hidden in the secret corners, as is often the case with play about themes of dying and death in early childhood settings (Corsaro, 2000; Holland, 2003; Levin, 2003). In the case of this research, the ethnography involved spending one day a week for a period of $1 \frac{1}{2}$ years in Westside Nursery ${ }^{2}$ in London as a semi-participant observer, joining children as a co-player when invited. This semi-participant positioning has been described elsewhere as attempting to be a 'least-educator'. It involved on-going reflection upon adult-child social relations whilst attempting to be situated 'outside of the institutionalised responsibilities and authority embedded in an educator role' (Albon and Rosen, 2014, p.38).

The process of turning field notes and transcriptions into lines of analysis was an iterative one which involved moving from descriptive to an increasingly analytic set of codes which focused on relationships both in and between the data, interactions, and processes. Whilst coding is intended as a way to help manage and organise the vast amounts of data generated in ethnographic studies, it inherently summarises or reduces data to decontextualised component parts. As a result, coding was complemented by in-depth analysis of 'critical moments', one of which will feature centrally in this article. The selection of 'critical moments' for analysis was not based on the logic of representation but on the logic of complexity and emergence (Sayer, 2000), where even if an event or phenomena is observed

\footnotetext{
${ }^{2}$ All names of people and places in the study are pseudonyms.
} 
only once it can still be interrogated in relation to the conditions of its production and the effects of its existence. Analytically, the use of critical moments which either 'disturb or jar' or 'are so mundane that we may miss their presence' allows for analysis of 'entrenched assumptions', social relations, and 'consideration of the ways these practices are "normalised"' (Albon and Rosen, 2014, p.6). In this article, one 'critical moment' will be examined in-depth and will be supplemented by discussion of broader trends and themes generated through the coding process.

Westside Nursery is a maintained, not-for-profit nursery, based in a low-income neighbourhood in West London. There are up to 80 children enrolled in the setting, 40 parttime and up to 40 full-time. Families receive the 15-hour national entitlement for nursery education with additional funding for full-timers provided by the national and local governments on the basis of 'need'. Children attending the setting range from 2-4 years old, speak over 15 home languages, and come from diverse religious, ethnic, and cultural communities. Some children in the setting had direct experience with dying and death; however, this was not the case for the majority. Beyond children's interactions in imaginative play, dying and death was rarely discussed by educators and children in either informal or formal interactions.

\section{A critical moment: Vicious monsters, dying and healing medicine}

Kaltrina and Nasra had initiated a game of peekaboo with me in the central part of the outdoor area when Abdul approached: growling, barking, and pulling on my pants with his teeth. 'I'm a friendly dog,' he said between snarls. 'Come. The jungle,' he continued, pulling me towards the treed area. Taking up the narrative, Kaltrina pointed into the distance behind us and shrieked: 'A monster! Hide in my house!' As we began running to the jungle-house, Nasra intervened bravely: 'I'll get a gun and kill it,' skipping off to look for a gun before joining us in the jungle-house.

Once inside the jungle-house, the 'doorbell' at the bottom of the muddy hill started ringing. Kaltrina ran to open the 'door' and many more children came in seeking refuge from the monster. Settled in safely, Maribel's eyes suddenly rolled back in her head until her lids fluttered closed and she slithered to the ground on top of my crouched body. 'I'm dead,' she whispered, lying motionless.

'Help!' I cried. 'She's dead! What should we do?' Nasra responded shyly, 'I'll be the doctor,' mixing potions and giving Maribel injections. But Maribel didn't move and didn't blink. Mark came roaring in with an ambulance siren blaring and set to work on Maribel. Nonetheless, he couldn't revive her either.

Seeing the action, Tanveer fell to the ground crying, 'I'm dying. I'm dying.' Peter and Nandan soon followed, sliding to the ground in 'death position'. Abdul-dog rushed over on his hands and knees growling, puffing, and bearing down on Tanveer. 'Hey,' 
shouted Tanveer angrily, pushing the dog off. Abdul-dog whimpered and rubbed against my leg. 'What happened, doggie?' I asked. 'My fire makes them better,' he replied plaintively, referring to his hot fiery breath. 'Do they know that?' I queried. Abdul-dog rushed over to Tanveer to explain. Tanveer relented: 'Ok, just a small one.'

Surveying the 'dead bodies' lying on the ground Nasra-doctor pointed to a small gated area next to the jungle-house: 'Medicine! Down here.' Abdul, Nasra, Kaltrina, and Mark trooped down, on the search for medicine to fix their compatriots. The narrative carried on for some time as the group of 'living' children continued to attempt various efforts to revive the dead and dying, some with more success than others.

Ludic death such as those noted in the critical moment above was a common occurrence at Westside Nursery, observed on a daily basis. Similar to the events in the 'jungle-house', the act of dying in play was often contagious: one death led to another and often mass deaths ensued. Indeed, Maribel's death, like the others which followed, was not provoked or caused by any apparent development in the narrative and ludic activity which might be expected to cause death, for example storylines involving weapon fights, did not result in death at Westside Nursery. Instead, mortality was consistently self-proclaimed.

Dying and death were often represented in an embodied manner, similar to the description of Maribel's closed eyes and flat, motionless body. On other occasions, children would extend their arms and legs or stick their tongue out of the side of their mouth. This physical caricature seemed to be a recognised symbol in the peer culture, only occasionally explained by a brief statement as with Maribel's explanation ('I'm dead!') or Tanveer's more active proclamation ('I'm dying!'). At other times, no verbal pronouncement was made in connection with the embodied action, but another child in the setting would explain or respond as if a 'death' had occurred.

In this critical moment, there were a variety of responses to the 'death' of a child player. With the assistance of others, Nasra and Mark attempted medicalised interventions using pharmaceuticals and injections. Abdul relied on a form of magic: hot and fiery dog breath. Magic and medical interventions - including CPR - were often used in revivals, but at other times in the ethnographic study children used kisses, tickles, and physical prodding. Occasionally deaths were ignored, as with Peter and Nandan, and these I will return to below.

Dying and death did not hold any sense of permanence in the play: it was treated as a reversible process. It was often momentary in everyday time and was unaccompanied by symbols in the ludic narrative suggesting that it was anything but temporary although some 
children did remain dead for longer periods as in Maribel's prolonged 10 minute death. The only exception here was that death was occasionally permanent for a ludic character: a 'goodie' character might be discarded through the act of dying in order to take up another character such as a zombie. Perhaps in keeping with the lack of permanence accorded to death, dying was never marked by any kind of ritual of mourning, such as covering the body, funeral, or expression of grief, with the exception of one child who 'cried' at a death scene and was observed with concern by the other players.

\section{The use of death as a generative metaphor}

If analysed through a literal conceptualisation of play, the apparently causeless and reversible deaths of Maribel, Tanveer, Peter, and Nandan in play seemingly supports developmental views discussed above that young children's understandings of death are limited and even incorrect. A figurative understanding of play, however, opens up other possibilities for analysing the repeated use of apparently causeless and reversible ludic deaths at Westside Nursery. Here the questions shift away from the individual child's emotional preoccupations and developmental trajectory towards questions about the meaning(s) carried by the symbolic act of death within the peer culture. The regularity with which death was enacted within the children's play and the relative stability of responses to ludic death within the peer culture are suggestive of the possible hopes these players had for its ability to provoke 'satisfying' responses from others (Henricks, 2006).

It is here that I want to suggest that within the peer culture, ludic death came to assume the status of a 'generative metaphor' (following Schön, 1993). Schön considers the way underlying 'stories' frame social dilemmas in particular ways and thereby generate particular 'solutions'. Primarily considering generative metaphors in relation to social policy, he offers the example of poor, inner-city communities, arguing that framing of the issue in terms of urban 'blight' prompts policy rooted in the concept of 'disease' and 'cure'; although, he notes that generative metaphors can also result in positive innovations. Generative metaphors are 'triggered' through intense and even embodied engagements where the characteristics of one phenomena or object are loosely 'mapped' on to the other. Bringing the features of one phenomena into conversation with another prompts entirely 'new perceptions, explanations, and inventions' (Schön, 1993, p.142).

In the case of the above fieldnote, Maribel's initial death can be viewed as a metaphor for a series of 'problems' encountered in the ludic activity. Here, it is relevant that her use of the death trope was not an obvious part of the on-going narrative and there was no problem within the narrative which seemed to cause her death. She did, however, face a series of 
significant challenges: she had not yet established a role for herself in the in-process play. Her position, continued participation, and level of influence over the narrative were relatively uncertain. Indeed, 'death' was often used in moments of particular uncertainty such as initiation of play interactions or power struggles over narrative developments.

The death trope became a relatively stable symbol called up by some children in the setting and was widely recognised by others. When mapped on to other 'problems' encountered in the ludic activity, 'death' offered the hope of a particular solution to problems of uncertainty in entering and influencing the play. Similar to the everyday world, dying and death was often productive of sustained emotional and physical attentions to the 'corpse' resulting in the player's embodied self being incorporated into the play narrative. In this case, Maribel's death prompted the ministrations of both Nasra and Mark. Even more, when death was responded to at Westside Nursery it generated a pivot or shift in the storyline allowing the dying player to exert a form of influence over the direction of the play narrative. In the case of Maribel, her continued death produced a narrative of collective exploration and quest for medicine to revive her which was not present prior to her use of the trope. This was a narrative which occupied others for some time and ensured Maribel a central role in the play.

Although it is less apparent in this critical moment, it is important to point out that use of the death trope was not always generative. Its impact and influence was often based on the position of the player within the setting: Peter and Nandan's bodies, for instance, were left

lying on the ground as the play moved on around them. As in the everyday world, some deaths were regarded as particularly emotive whilst others were overlooked, little more than collateral damage. Beyond the implications for the reproduction of inequitable social relations, this testifies to the lack of predictability of meanings and acts in play.

\section{Using imaginative death to provoke caring touch}

To this point, it has been suggested that the death trope in play narratives at Westside Nursery can be viewed as a generative metaphor which mapped on to problems of entering and influencing play narratives. Notably here, the use of the death trope at Westside Nursery was one that generated and enabled close physical proximity and even caring touch between children. Whilst early fieldnotes taken in the ethnography were replete with comments about the physical proximity of the children's play - where entangled bodies in close spaces made breath, scent, and touch central to the experience - the presence of a 'death' in the narrative seemed to do more. It made intimate touch permissible, rather than just a by-product of small spaces filled with many bodies; but even more, it demanded intimate touch. 
When the children in the critical moment above died, they seemed to anticipate - or at least hope for - a healing response from others. Their deaths occurred in open spaces and in front of others, often directly in their path as in Maribel's original demise. Regardless of the narrative theme of the play, virtually every revival or healing response to ludic death involved close physical contact. This suggests that revival became associated with a variety of forms of close and intimate physical contact amongst players at Westside Nursery. There seemed to be little concern that intimate touch would be misinterpreted, disavowed, or negatively responded to by the child who died. This acceptance of touch sits in stark contrast to the uncertain status of physical touch at other times during the children's play: players may have positioned themselves in close proximity but that did not preclude pushing and anger at another's touch in these moments.

The death trope, then, served not only as a generative metaphor generally but as a provocation for intimate physical contact, an affordance of the at-risk or in-need corpse symbolised by a motionless and defenceless body. The point here is not to argue that play about death is the only time children initiate any form of physical intimacy but to point to the way that the death trope emerged as a particular way in which caring touch from others was invoked at Westside Nursery. Notably here, the embodied invitation for physical proximity and touch was issued to peers. In part this contention draws its weight from the context of early childhood settings where play is primarily constructed as the purview of children (Ailwood, 2003). It has a particular resonance in Westside Nursery as educators rarely engaged in extended periods of ludic activity with children particularly in relation to death play. In the moments when educators did interact with children's death play this was often limited in form by the children's interpretations and responses. Children jumped up from death position when an educator questioned their activity only to return when the educator had left. At another time, they 'humoured' an educator who wanted to tickle the child's motionless body, returning to their revivals - in that case administering a kiss of life in what seemed to be a loose citation of Sleeping Beauty - when the educator left.

At one level, these ludic practices echo charges that requirements for 'personal space' are socially constructed, not just in terms of how much space is needed but in terms of whether bodily 'space' is needed at all. Perhaps more fundamentally, the use of the death trope challenges the insistence in Western, and certainly Anglo-North American early years settings, about maintaining and developing a sense of corporeal containment, linked to individualism and separateness from others. Familiar directives issued in early years settings including Westside Nursery such as: 'Move over and give Jenny space', 'Keep your hands on your own body', or 'You can pretend to fight but don't touch each other's bodies' exemplify this in a very concrete way. An emphasis on developing a sense of a bounded 
body lingers beneath many other common practices in the UK (e.g. see Jones et al., 2010), such as requiring children to sit with their bodies separated at group times. These policies and practices have their roots in ideas about what constitutes appropriate behaviour and 'school-readiness' where children's proximity and touch is seen to be disorderly and therefore threatening to underlying assumptions that 'order precedes learning' (Phelan, 1997, p.77).

Elias (1994) refers to efforts to contain and privatise the body as a process of 'progressive individualization', a social process of modernity rather than natural necessity. The 'self in a case', Elias (1994, p.207) argues, is produced through 'civilizing' processes where bodily matters are increasingly regulated and subject to social taboos in efforts to, for instance, delineate humanity in opposition to animality which the supposedly unclean or untamed body threatens and as a way of attributing value or status to 'mannered', and essentially classed, bodies. Self-regulation of bodily action, affect, and even corporeality itself comes to be so taken-for-granted that people do not question these 'habits'; those who violate such modes of being, however, are considered either 'impossible' and 'pathological' or children who will learn the desired etiquette, ultimately reinforcing the separation and indeed denigration of childhood (Elias, 1994, p.116). This process of separating bodies serves to build affective walls between people and their bodies, as well as their bodies and others (Shilling, 2003). The use of the death trope in Westside Nursery to provoke caring touch can be seen in this light to strain at corporeal containment identified with modernity's individualism. Indeed, Manning (2007, p.xviii) argues that touch is a 'reaching toward' which 'at its most political... is to create a concept for unthinking the individual as a discrete entity...mov[ing] toward something that is not yet'.

The use of the death trope in this and other critical moments also challenges notions of children as fundamentally dependent on independent adults, a result of the overextension of biological dependency of infancy onto all aspects of children's lives (Mayall, 2004). In generational relations shaped by such perspectives, care is constituted as that which is provided by adults for children. In early childhood settings, for instance, the influence of attachment theorising has been widely interpreted as a dyadic relationship between educator and child in which care is undertaken by the educator (Pearson and Degotardi, 2009). In contrast, players' uses and responses to the death trope at Westside Nursery was suggestive of their desires to be intimately cared for by other children, at very least within ludic spaces. Their often caring responses suggest that young children are capable of 'attentiveness' (Tronto, 1989, p.177), an effort of awareness to the particular needs of another through caring touch as well as other more affective/emotional means. Whilst these relations of caring and revival took place in the ludic world, the embodied nature of 
imaginative play allows for the affective and haptic sensations of caring relations to traverse into player's everyday world selves.

In the act of caring for players who were dead and dying, it is possible to understand the player(s) as bringing a sense of value and meaning to the child-corpse which exceeds an instrumental and individualising logic. Perhaps this provides an explanation of the continued use of the death trope in this critical moment and beyond. The gathering of players around a 'corpse', a coming together of bodies in space, offers something of what Bakhtin (1984, p.23) describes in relation to the Medieval Carnival where people could feel themselves, at least momentarily, as part of a bigger whole rather than 'atomized' and alienated: an embodied sense of social collectivity.

\section{Conclusion}

This article has considered the presence of dying and death in children's play at one early childhood setting in London, UK. Not only does interpreting such play only through a literal lens run the risk of reproducing deficit views of children, it also fundamentally misses the transformative nature of play where new and movable meanings are created and invoked by players seeking 'satisfying' responses to their ludic actions. In taking a figurative view of play, it has been demonstrated that the use of the death trope in this particular peer culture can best be understood as a generative metaphor which players used to enter and maintain a presence within the play narrative as well as to promote proximity, touch, and physical connection. It is highly unlikely that the death trope would assume similar meanings and productivities in other settings, as ludic meanings are not only movable but are also extremely contextual. The consequences of the argument contained in this article are, however, relevant beyond this setting, both in terms of ludic and everyday realms. In the ludic realm, the implication is that there is a need to consider young children's play beyond developmental and educational assumptions: the meanings enacted in playful activity greatly exceed the possibilities afforded in the everyday world.

Whilst the article has been at pains to stress that the meanings of the death trope are best understood figuratively rather than as literal expressions of children's preoccupations and understandings, I want to conclude by pointing to two implications of this analysis for the everyday world. First, players' on-going efforts at care and revival of the dead and dying in ludic activity at Westside Nursery are suggestive that children cannot be constituted a priori as lacking the ability or 'nature' to care for others. Whilst this is not an argument that children should be put to work caring for those who are dying or valorising informal care work which is highly gendered and undervalued in the everyday world, it is to suggest that being 
involved in caring is - for some children - a desirable role. Importantly here, participating in caring - both in play and in the everyday world - can offer a sense of value to both those being cared for and those doing the caring.

Secondly, regardless of children's cognitive understandings of dying and death in Westside Nursery, death was clearly available as reference point in their play despite having an ambiguous 'absence presence' for educators at Westside Nursery. This suggests that dying and death are not aspects of the everyday world which children can be easily 'protected' from. Instead, the widespread sequestration of death and dying from children (Stanley and Wise, 2011) is a reflection of contemporary constructions of childhood innocence and vulnerability which have little relation to the complex lives of real children. What's more, the extensive use of the death trope in children's play away from, although not separate from or invisible to, adults suggests awareness amongst the child players that such themes were considered taboo by many educators in this setting. This served to drive explorations of death and dying underground into peer groups. In effect, this diminished the possibilities for adults and children to make sense of together, or indeed play with, the difficult and challenging nature of death and the issues for which it served as a metaphor.

\section{References}

Ailwood, J. (2003). 'Governing early childhood education through play'. Contemporary Issues in Early Childhood, 4 (3), 286-299.

Albon, D. and Rosen, R. (2014). Negotiating Adult-child Relationships in Early Childhood Research. London: Routledge.

Arnason, A. and Hafsteinsson, S. B. (2003). 'The revival of death: Expression, expertise and governmentality'. The British Journal of Sociology, 54 (1), 43-62.

Bakhtin, M. M. (1984). Rabelais and His World. (1st Midland book ed. ed.). Bloomington: Indiana University Press.

Bateman, A., Danby, S. and Howard, J. (2013). 'Living in a broken world : how young children's well-being is supported through playing out their earthquake experiences'. International Journal of Play, 2 (3), 202-219.

Boyden, J. (1997). 'Childhood and the policy makers: A comparative perspective on the globalization of childhood'. In A. James and A. Prout (Eds), Constructing and Reconstructing Childhood: Contemporary issues in the sociological study of childhood (2nd ed., pp. 187-225). London: Falmer P. Available [Online] at: http://elibrary.ioe.ac.uk/login?url=http://www.dawsonera.com/depp/reader/protected/e xternal/AbstractView/S9780203362600.

Corsaro, W. (2000). 'Early childhood education, children's peer cultures, and the future of childhood'. European Early Childhood Education Research Journal, 8 (2), 89-102.

Cox, M., Garrett, E. and Graham, J. A. (2004/2005). 'Death in Disney Films: Implications for children's understanding of death'. Omega: Journal of Death \& Dying, 50 (4), 267280.

Dahlberg, G., Moss, P. and Pence, A. (2007). Beyond Quality in Early Childhood Education: Languages of evaluation. (2nd ed.). London: Routledge.

DCSF. (2008). Statutory Framework for the Early Years Foundation Stage. Nottingham: Department for Children, Schools, and Families.

Elias, N. (1994). The Civilizing Process. Oxford: Blackwell. 
Fromberg, D. P. (2002). Play and Meaning in Early Childhood Education. Boston: Allyn \& Bacon.

Fromberg, D. P. and Bergen, D. (2006). 'Introduction'. In D. P. Fromberg and D. Bergen (Eds), Play From Birth to Twelve: Contexts, Perspectives, and Meanings (2nd ed., pp. XV-xxi). New York: Routledge.

Goldstein, J. (1995). 'Agressive toy play'. In A. Pellegrini (Ed.), Future of Play Theory (pp. 127-150). New York: State University of New York Press.

Grieshaber, S. and McArdle, F. (2010). The Trouble with Play. Maidenhead: Open University Press.

Hammersley, M. and Atkinson, P. (2007). Ethnography: Principles in practice. (3rd ed.). Milton Park, Oxon: Routledge.

Henricks, T. S. (2006). Play Reconsidered: Sociological perspectives on human expression. Urbana, III.: University of Illinois Press.

Holland, P. (2003). We Don't Play with Guns Here: War, weapon and superhero play in the early years. Maidenhead: Open University Press.

Jones, L., Holmes, R., MacRae, C. and MacLure, M. (2010). "'Improper" children'. In N. Yelland (Ed.), Contemporary Perspectives on Early Childhood Education (pp. 177191). Maidenhead: Open University Press.

Lee, R. L. M. (2008). 'Modernity, mortality and re-enchantment: The death taboo revisited'. Sociology, 42 (4), 745-759.

Levin, D. E. (2003). 'Beyond banning war and superhero play: Meeting children's needs in violent times'. Young Children, 58 (3), 60-66.

Löfdahl, A. (2005). "The funeral': A study of children's shared meaning-making and its developmental significance'. Early Years, 25 (1), 5-16.

Manning, E. (2007). Politics of Touch: Sense, movement, sovereignty. Minneapolis, Minn.; London: University of Minnesota Press.

Mayall, B. (2004). 'Sociologies of childhood'. In M. Holborn (Ed.), Developments in Sociology: An annual review (Vol. 20, pp. 37-57). Ormskirk: Causeway Press.

Pearson, E. and Degotardi, S. (2009). 'Relationship theory in the nursery: Attachment and beyond'. Contemporary Issues in Early Childhood, 10 (2), 144-155.

Phelan, A. M. (1997). 'Classroom management and the erasure of teacher desire'. In J. Tobin (Ed.), Making a Place for Pleasure in Early Childhood Education (pp. 76-100). New Haven and London: Yale University Press.

Robinson, K. H. (2013). Innocence, Knowledge, and the Construction of Childhood: The contradictory nature of sexuality and censorship in children's contemporary lives. London: Routledge.

Sayer, A. (2000). Realism and Social Science. Thousand Oaks, Calif. ; London: Sage.

Schön, D. (1993). 'Generative metaphor: A perspective on problem-setting in social policy'. In A. Ortony (Ed.), Metaphor and Thought (2nd ed. ed., pp. 137-163). Cambridge: Cambridge University Press.

Shilling, C. (2003). The Body and Social Theory. (2nd ed.). London: Sage.

Stanley, L. and Wise, S. (2011). 'The domestication of death: The sequestration thesis and domestic figuration'. Sociology, 45 (6), 947-962.

Sutton-Smith, B. (1997). The Ambiguity of Play. Cambridge, Massachusetts: Harvard University Press.

Tronto, J. (1989). 'Women and caring: What can feminsts learn about morality from caring?'. In A. M. Jaggar and S. R. Bordo (Eds), Gender/Body/Knowledge (pp. 172-187). London: Rutgers University Press.

Vygotsky, L. S. (1978). Mind in Society: The development of higher psychological processes. Cambridge, Massachusetts: Harvard University Press.

Wass, H., Dinklage, R., Gordon, S. L., Russo, G., Sparks, C. W. and Tatum, J. (1983). 'Use of play for assessing children's death concepts: A reexamination'. Psychological Reports, 53, 799-803.

Wood, E. (2012). 'The state of play'. International Journal of Play, 1 (1), 4-5. 
Wood, E. (2013). Play, Learning and the Early Childhood Curriculum. (3rd ed.). Los Angeles ; London: Sage. 